\title{
Limited need for hospital resources among patients brought to hospital by the emergency medical services
}

\author{
Carl Magnusson ${ }^{1,2^{*}}$, Helena Ryge ${ }^{2}$, Filip Scott ${ }^{2}$, Johan Herlitz ${ }^{3}$ and Christer Axelsson ${ }^{2,3}$
}

\begin{abstract}
Background: In Sweden, the majority of patients who are transported to hospital by the emergency medical services (EMS) are relatively old and the majority suffer from comorbidity. About half these patients are admitted to a hospital ward and will stay in hospital. However, the other half will only make a visit to the emergency department (ED). The burden on the ED is extensive and many elderly patients have to stay for many hours in the ED.

Aim: To describe the patients who are brought to hospital by the EMS, with particular emphasis on those that were discharged from the ED, and to assess the proportion of these patients who did not require hospital resources, which could mean that they were candidates for primary care (PC).

Methods: An observational analysis of a cohort of patients who were transported to hospital by the EMS in 2016 in the Municipality of Gothenburg.

Results: In all, 5,326 patients were transported to hospital by the EMS of which 52\% were discharged directly from the ED. These patients included $37 \%$ assessed as not requiring hospital resources. The three most common causes of contact with the EMS in this subset were abdominal pain (15\%), back pain (8\%) and non-specified disease (7\%). Of these patients, $77 \%$ had contact with a physician in the ED, whereas $6 \%$ had contact with a nurse and $17 \%$ left the ED without any contact. Twenty-six per cent were given advice on follow-up in PC.

Conclusions: Among patients who were brought to hospital by the EMS, more than half were discharged directly from the ED. Among these patients, 37\% were assessed as not requiring hospital resources. These patients comprised $15 \%$ of the overall study cohort and may be candidates for primary care.
\end{abstract}

Keywords: Emergency Medical Service, Emergency Department, Hospital Resources

\section{Introduction}

One of the key problems in emergency care is the long time many patients have to wait in emergency departments (ED), which is a risk factor for patient safety and low-quality care [1] and which also creates frustration for the patients. This is particularly problematic among

\footnotetext{
* Correspondence: carl.magnusson@vgregion.se

'Institute of Medicine, Department of Molecular and Clinical Medicine, Sahlgrenska Academy, University of Gothenburg, Gothenburg, Sweden

${ }^{2}$ Department of Prehospital Emergency Care, Sahlgrenska University Hospital, Gothenburg, Sweden

Full list of author information is available at the end of the article
}

the elderly. It has thus been reported that patients aged $>80$ years spend a mean of four hours and eight minutes in the ED as compared with patients aged 18-79 years who spend a mean of three hours and 10 minutes in the ED [2]. Simultaneously, an association has been reported between the number of patients assembled in the ED and the risk of death among patients aged $>80$ years. An increased risk of death has also been reported if the waiting time in the ED among the elderly is more than eight hours [3].

C C The Author(s). 2021 Open Access This article is licensed under a Creative Commons Attribution 4.0 International License, which permits use, sharing, adaptation, distribution and reproduction in any medium or format, as long as you give appropriate credit to the original author(s) and the source, provide a link to the Creative Commons licence, and indicate if changes were made. The images or other third party material in this article are included in the article's Creative Commons licence, unless indicated otherwise in a credit line to the material. If material is not included in the article's Creative Commons licence and your intended use is not permitted by statutory regulation or exceeds the permitted use, you will need to obtain permission directly from the copyright holder. To view a copy of this licence, visit http://creativecommons.org/licenses/by/4.0/ The Creative Commons Public Domain Dedication waiver (http://creativecommons.org/publicdomain/zero/1.0/) applies to the data made available in this article, unless otherwise stated in a credit line to the data. 
Many EDs have problems with a high burden of admissions, but, simultaneously, a limited number of beds are available within the hospital. Patients for whom hospitalisation has been determined remain in the ED for hours due to the lack of beds and, at the same time, new admissions are increasing the ED burden still further.

The EMS in Gothenburg, Sweden, handles approximately 60,000 primary missions each year and the median age of these patients is 66 years. Among them, $20 \%$ are not conveyed, with advice on self-care or with a referral to PC. Among the remaining patients, $90 \%$ are transported directly to the ED and $10 \%$ enter a "fast track", bypassing the ED to a directed investigation or treatment [4]. The latter group includes patients with a suspected hip injury, stroke or myocardial infarction.

In order to relieve the burden of patients on the ED, many EMS systems in Sweden have developed different "chains of care", with the overall aim of reducing the level of care. These new "chains of care" can result in either advice on self-care or a referral to PC. However, despite these aims, the majority (80\%) of patients who are assessed by the EMS are still transported to the ED [4]. However, a significant proportion of the patients who are transported to the ED by the EMS are "low acuity patients" in terms of the severity of disease and they are in fact candidates for a lower level of care [5]. One of the reasons for this finding may be that there are no natural ways from the EMS to primary care $(\mathrm{PC})$ and $\mathrm{PC}$ is mostly not available in out-of-office hours.

In order to create secure, safe care for patients, there are two basic requirements: 1 ) continuity and 2) an appropriate level of care.

The aim of this survey was to describe the patients who are transported to hospital by the EMS, with particular emphasis on those who were directly discharged from the ED. Based on clear definitions, the primary aim was therefore to estimate the proportion of these patients who did not require hospital resources, since a group of this kind may be candidates for a lower level of care.

\section{Methods}

\section{Catchment area and organisation}

The Municipality of Gothenburg has an area of $900 \mathrm{~km}^{2}$ and a population of 660,000 people. There are 19 ambulances within the EMS system, of which the majority are available for 24 hours seven days a week. In addition, there are a few vehicles with specific tasks including three single responders for non-emergency cases, one physician-manned unit for cases where a higher competence level is required and one scene-command unit to support more extensive events.

\section{Competence in the ambulance}

According to the Swedish National Board of Health and Welfare, every single ambulance in Sweden should be manned by at least one registered nurse (RN) who is allowed to administer medication. In the study area, each ambulance during the study period was therefore manned by at least one RN and one emergency medical technician (EMT). The majority of the RN:s have a postgraduate education specialising in prehospital emergency care, intensive care or anaesthesia care.

\section{Decision support tool}

The Rapid Emergency Triage and Treatment System (RETTS) is used both in the EDs within the hospital and in the prehospital setting in $95 \%$ of the regions in Sweden in order to triage patients. The RETTS consists of measurements of vital signs (VS) and an emergency signs and symptoms (ESS) code which is defined on the basis of cause of contact and symptoms.

When VS and ESS are considered simultaneously, a recommendation on priority level is given by the system.

The priority is divided into five levels, i.e. blue, green, yellow, orange and red.

Blue means that alternatives other than the ED may be appropriate. At the time of the study, this colour was not used when triaging in the prehospital setting. The other four colours mean increasing severity from green to red and the risk of death is expected to increase accordingly.

\section{Selection of cases}

Case selection took place from 1 January until 31 December 31 in 2016. In all, there were 82,000 missions during that year. Among these cases, the first 1,000 were selected each month for the study. After excluding secondary missions (mission without a primary patient assessment), a total of 8,019 patients remained in the study cohort. Among them, 1,307 were excluded due to age $<16$ years, patients with incomplete medical records or doublets, patients who died at the scene or for whom a hospital case record was not available.

Among the remaining 6,712 patients, 1,372 were left at the scene and 5,340 patients were transported to hospital (missing information in 14 cases).

This study is based on these 5,326 patients who were transported to hospital, with primary emphasis on the patients who were discharged directly from the ED.

\section{Case evaluation}

The 2,695 patients who were discharged from the ED were divided into two groups: 1 ) patients who required the use of hospital resources (resources that were considered specific to the hospital and which were not 
available in $\mathrm{PC}$ ) and 2) patients who did not require these resources.

The resources that were considered specific to the hospital and were not available in PC were defined as follows.

1) Assessment by a specialist (in neurology, cardiology, infectious diseases, gynaecology etc.);

2) Assessment for the risk of suicide;

3) Extended investigations (computed tomography, ultrasound, lumbar puncture, magnetic resonance imaging, X-ray and scopies);

4) Extended blood sampling (Troponin, d-dimer, NT pro BNP, blood concentrations of drugs);

5) Observation - stayed in the ED for a few hours of observation;

6) Emergency treatment

7) Other (referral from PC)
Group 2 consisted of the patients who were not thought to require hospital resources. Many of these patients had met the physician on call in the department of psychiatry, medicine, orthopaedics and surgery. Many of these patients had undergone a general examination, including basic blood sampling and an ECG recording. Many of them had been given medication, including pain relief and inhalations. Even uncomplicated allergic reactions were considered to belong to a lower level of care, i.e. PC, and were therefore not in need of transport to hospital.

\section{Statistical methods}

The results are presented as frequencies, proportions, the median and $25 \%$ and $75 \%$ percentiles. Table 1 shows all the patients who were transported to hospital. Tables 2, 3, 4 and 5 show patients who were assessed and treated in the

Table 1 Patients assessed by the EMS nurse as requiring hospital resources in relation to whether discharged from the ED

\begin{tabular}{|c|c|c|c|}
\hline & $\begin{array}{l}\text { All } \\
n=5326\end{array}$ & $\begin{array}{l}\text { Hospitalised } \\
n=2631\end{array}$ & $\begin{array}{l}\text { Discharged from ED } \\
n=2695\end{array}$ \\
\hline \multicolumn{4}{|c|}{ Age - years (25th, 75th percentiles) } \\
\hline Median & $68(44,83)$ & $76(59,85)$ & $56(34,76)$ \\
\hline \multicolumn{4}{|l|}{ Gender - n (\%) } \\
\hline Female & $2756(51.7)$ & $1344(51.1)$ & $1412(52.4)$ \\
\hline Male & $2570(48.3)$ & $1287(48.9)$ & $1283(47.6)$ \\
\hline \multicolumn{4}{|c|}{ RETTS ESS code $-n(\%)^{1}(160,78,82)^{2}$} \\
\hline Abdominal pain & $534(10.3)$ & $206(8.1)$ & $328(12.6)$ \\
\hline Chest pain & $512(9.9)$ & $256(10.0)$ & $256(9.8)$ \\
\hline Dyspnea & $454(8.8)$ & $334(13.1)$ & $120(4.6)$ \\
\hline Trauma, head & $323(6.3)$ & $81(3.2)$ & $242(9.3)$ \\
\hline Non-specific disease & $349(6.8)$ & $221(8.7)$ & $128(4.9)$ \\
\hline Intoxication & $251(4.9)$ & $130(5.1)$ & $121(4.6)$ \\
\hline Vertigo & $191(3.7)$ & $94(3.7)$ & $97(3.7)$ \\
\hline Trauma, hip/leg & $186(3.6)$ & $136(5.3)$ & $50(1.9)$ \\
\hline Infection & $137(2.7)$ & $109(4.3)$ & $28(1.1)$ \\
\hline Back pain & $130(2.5)$ & $30(1.2)$ & $100(3.8)$ \\
\hline \multicolumn{4}{|l|}{ Triage colour - n (\%) } \\
\hline Red & $596(11.6)$ & $487(19.1)$ & $109(4.2)$ \\
\hline Orange & $1853(35.9)$ & $992(39.0)$ & $861(33.0)$ \\
\hline Yellow & $2247(43.6)$ & $928(36.5)$ & $1319(50.5)$ \\
\hline Green & $459(8.9)$ & $137(5.4)$ & $322(12.3)$ \\
\hline Triage colour missed & $171(3.2)$ & $87(3.3)$ & $84(3.1)$ \\
\hline \multicolumn{4}{|c|}{ Time of day and night - n (\%) } \\
\hline $8-16$ & $2424(45.5)$ & $1286(48.9)$ & $1138(42.2)$ \\
\hline $16-22$ & $1523(28.6)$ & $749(28.5)$ & $774(28.7)$ \\
\hline $22-08$ & $1379(25.9)$ & $596(22.7)$ & $783(29.1)$ \\
\hline
\end{tabular}

${ }^{1}$ Ten most common ESS codes

${ }^{2}$ Number of missions with missing ESS code 
Table 2 Patients in need of emergency department resources

\begin{tabular}{|c|c|c|c|c|c|}
\hline \multirow[b]{2}{*}{ Type of resources $^{1}-\mathrm{n}(\%)$} & \multirow[b]{2}{*}{ All } & \multicolumn{2}{|l|}{ GENDER } & \multicolumn{2}{|l|}{ AGE } \\
\hline & & Female & Male & $<56$ years & $\geq 56$ years \\
\hline OR $(95 \% \mathrm{Cl})^{2}$ & 1689 & 899 & 790 & 803 & 886 \\
\hline Specialist evaluation & $220(13.0)$ & $124(13.8)$ & $0.87(0.65-1.15)$ & $111(13.8)$ & $0.88(0.66-1.16)$ \\
\hline Suicide evaluation & $55(3.3)$ & $36(4.0)$ & $0.59(0.34-1.04)$ & $45(5.6)$ & $0.19(0.10-0.38)$ \\
\hline Extended evaluation ${ }^{3}$ & $852(50.4)$ & $438(48.7)$ & $1.16(0.96-1.40)$ & $396(49.3)$ & $1.09(0.90-1.32)$ \\
\hline Blood sampling & $438(25.9)$ & $243(27.0)$ & $0.89(0.71-1.10)$ & $172(21.4)$ & $1.57(1.26-1.96)$ \\
\hline Observation & $65(3.8)$ & $33(3.7)$ & $1.11(0.68-1.82)$ & $48(6.0)$ & $0.31(0.18-0.54)$ \\
\hline Emergency care & $39(2.3)$ & $16(1.8)$ & $1.66(0.87-3.16)$ & $18(2.2)$ & $1.06(0.56-2.00)$ \\
\hline Other ${ }^{4}$ & $20(1.2)$ & $9(1.0)$ & $1.40(0.58-3.39)$ & $13(1.6)$ & $0.48(0.19-1.22)$ \\
\hline
\end{tabular}

${ }^{1}$ Each patient belongs to only one category in decreasing order

${ }^{2}$ OR: odds ratio, $95 \%$ confidence interval

${ }^{3}$ Computed tomography, ultrasound, lumbar puncture, magnetic resonance imaging, $\mathrm{X}$-ray, scopies

${ }^{4}$ Patients with referral from primary care; ED physician want to admit but the patient opposes it.

ED but who were then discharged from the ED and were therefore never admitted to a hospital ward.

Table 1 shows age, gender, the 10 most common RETTS ESS codes among all cases, triage colours and the time of day of admission to the ED.

In Tables 2 and 3, patients who did and did not require specific hospital resources are presented as overall numbers and in subsets according to the type of resources used (Table 2) and various actions if no hospital resources were required (Table 3 ). In both tables, the results are also presented according to gender and age.

In the statistical analyses, odds ratios (OR) univariate and $95 \%$ confidence intervals (CI) and p-values were used. All p-values are two-sided and p-values below 0.05 were considered significant. In Tables 2 and 3, women and age below the median comprised the references in the calculation of OR and 95\% CI.

In Tables 4 and 5, the two groups assessed as needing and not needing hospital resources have been compared. In Table 4, patients have been divided into quartiles among all patients. Age 16-33 years, women, dispatch priority 1 , triage colour red, no previous disease and time of day 08-16 comprised the references. Time of day was categorised in relation to when $\mathrm{PC}$ was available (08-16).

In Table 5, patients needing and not needing hospital resources are compared regarding the 15 most common ESS codes for all patients who were discharged from the ED.

SPSS version 25 (IBM Corp, Armonk, NY) was used for data processing and statistical analyses were performed in R-studio version 1.2.5 (RStudio Inc., Boston, MA).

\section{Results}

In the study population, 5,326 patients were transported to hospital by the EMS. Among these patients, 2,631 (49.4\%) were hospitalised and 2,695 (51.6\%) were discharged from the ED. Among the 2,695 patients who were discharged from the ED, we found that 1,006 (37.4\%) did not use any of the resources which by definition were unique to the hospital (Figure 1).

\section{A comparison between patients who were and were not hospitalised (Table 1)}

Patients who were hospitalised had a median age which was 20 years higher than those who were not hospitalised, whereas the distribution of gender did not differ.

Table 3 Patients not in need of hospital resources

\begin{tabular}{|c|c|c|c|c|c|}
\hline \multirow[b]{2}{*}{ Type of evaluation ${ }^{1}-\mathrm{n}(\%)$} & \multirow[b]{2}{*}{ All } & \multicolumn{2}{|l|}{ GENDER } & \multicolumn{2}{|l|}{ AGE } \\
\hline & & Female & Male & $<56$ years & $\geq 56$ years \\
\hline OR $(95 \% \mathrm{Cl})^{2}$ & 1006 & 513 & 493 & 522 & 484 \\
\hline Contact with physician, treatment with or prescription of drugs & $332(33.0)$ & $178(34.7)$ & $0.86(0.66-1.11)$ & $155(29.7)$ & $1.37(1.05-1.78)$ \\
\hline Contact with a physician & $446(44.3)$ & $225(43.9)$ & $1.04(0.81-1.33)$ & $214(41.0)$ & $1.33(1.03-1.70)$ \\
\hline Contact with a nurse & $56(5.6)$ & $24(4.7)$ & $1.41(0.82-2.44)$ & $36(6.9)$ & $0.58(0.33-1.02)$ \\
\hline Patient left the scene & $172(17.1)$ & $86(16.8)$ & $1.05(0.76-1.46)$ & $117(22.4)$ & $0.44(0.31-0.63)$ \\
\hline Follow-up at a lower level of care ${ }^{3}$ & $259(25.7)$ & $122(23.8)$ & $1.23(0.93-1.64)$ & $120(23.0)$ & 1.35 (1.02-1.79) \\
\hline
\end{tabular}

${ }^{1}$ Each patient belongs to only one category in decreasing order

${ }^{2}$ OR: odds ratio, $95 \%$ confidence interval

${ }^{3}$ Patients for whom the emergency department physician, nurse, wants a follow-up in primary care, alcohol-dependence clinic, reception 
Table 4 Patient characteristics and prehospital assessment in relation to need for hospital resources among patients discharged from the ED

\begin{tabular}{|c|c|c|c|c|}
\hline Need for hospital resources & & No & Yes & OR (univariate) $^{1}$ \\
\hline & & $n=1006$ & $n=1689$ & \\
\hline \multirow[t]{4}{*}{ Age (years) ${ }^{2}$} & $16-33$ & $254(25.2)$ & $392(23.2)$ & \\
\hline & $34-55$ & $268(26.6)$ & $411(24.3)$ & $0.99(0.80-1.24, p=0.955)$ \\
\hline & $56-75$ & $251(25.0)$ & $434(25.7)$ & $1.12(0.90-1.40, p=0.315)$ \\
\hline & $>75$ & $233(23.2)$ & $452(26.8)$ & $1.26(1.01-1.57, p=0.045)$ \\
\hline \multirow[t]{2}{*}{ Gender } & Female & $513(51.0)$ & $899(53.2)$ & \\
\hline & Male & $493(49.0)$ & $790(46.8)$ & $0.91(0.78-1.07, p=0.262)$ \\
\hline \multirow[t]{3}{*}{ Dispatch $(17)^{3}$} & Prio 1 & $432(43.3)$ & $859(51.1)$ & \\
\hline & Prio 2 & $509(51.0)$ & $763(45.4)$ & $0.75(0.64-0.89, p=0.001)$ \\
\hline & Prio 3 & $57(5.7)$ & $58(3.5)$ & $0.51(0.35-0.75, p=0.001)$ \\
\hline \multirow[t]{4}{*}{ Triage colour (84) } & Red & $14(1.4)$ & $95(5.8)$ & \\
\hline & Orange & $234(23.9)$ & $627(38.4)$ & $0.39(0.21-0.68, p=0.002)$ \\
\hline & Yellow & $549(56.1)$ & $770(47.2)$ & $0.21(0.11-0.35, p<0.001)$ \\
\hline & Green & $181(18.5)$ & $141(8.6)$ & $0.11(0.06-0.20, p<0.001)$ \\
\hline \multirow[t]{4}{*}{ Previous history } & Healthy & $181(18.0)$ & $329(19.5)$ & \\
\hline & 1 & $208(20.7)$ & 331 (19.6) & $0.88(0.68-1.12, p=0.299)$ \\
\hline & 2 & $187(18.6)$ & $269(15.9)$ & $0.79(0.61-1.03, p=0.078)$ \\
\hline & $\geq 3$ & $430(42.7)$ & $760(45.0)$ & $0.97(0.78-1.21, p=0.800)$ \\
\hline \multirow[t]{3}{*}{ Time of day } & $08-16$ & $392(39.0)$ & $746(44.2)$ & \\
\hline & $16-22$ & $316(31.4)$ & $458(27.1)$ & $0.76(0.63-0.92, p=0.005)$ \\
\hline & $22-08$ & $298(29.6)$ & $485(28.7)$ & $0.86(0.71-1.03, p=0.105)$ \\
\hline Alcohol/drugs & Yes & $128(12.7)$ & $188(11.1)$ & $0.86(0.68-1.09, p=0.214)$ \\
\hline Medication & Yes & $215(21.4)$ & $458(27.1)$ & $1.37(1.14-1.65, p=0.001)$ \\
\hline
\end{tabular}

${ }^{1}$ OR: odds ratio, $95 \%$ confidence interval

${ }^{2}$ Age, categorised by quartiles

${ }^{3}$ Number of patients with missing information

Among all patients, the three most common ESS codes in order of frequency were: 1) abdominal pain (10.3\%); 2) chest pain (9.9\%) and 3) dyspnea (8.8\%). Among the patients who were hospitalised, the three most common ESS codes were: 1) dyspnea; 2) chest pain and 3) nonspecific disease, whereas, among the patients who were discharged from the ED, the three most common ESS codes were: 1) abdominal pain, 2) chest pain and 3) head trauma.

The proportion of patients who were triaged to red by the EMS at the scene was $19.1 \%$ among patients who were hospitalised versus $4.2 \%$ among patients who were discharged from hospital.

\section{Patients in need of hospital resources (Table 2)}

Among the patients who were assessed as being in need of hospital resources, 50.4\% required an extended evaluation and $25.9 \%$ required extended blood sampling. A suicide evaluation was more common among younger patients, whereas extended blood sampling was more common among the elderly.
Patients not in need of hospital resources (Table 3)

Among the patients who were assessed as not being in need of hospital resources, $44.3 \%$ had contact with a physician and $33.0 \%$ had contact with a physician and were given medication either directly or on prescription. Advice on follow-up in PC was given to $26 \%$ of the patients. The elderly more frequently had contact with a physician, were more frequently given medication and were more frequently advised to go for a follow-up in PC.

\section{Characteristics of patients who required hospital resources (Table 4)}

Patients aged $>75$ years more frequently required hospital resources. Patients who received priority 2 and 3 at dispatch, as well as patients who were triaged yellow and green by the EMS nurse, less frequently required hospital resources. Patients who sought care between 16.0022.00 less frequently required hospital resources as compared with those who sought care during the daytime. 
Table 5 Prehospital assessment according to RETTS in relation to need for hospital resources

\begin{tabular}{|c|c|c|c|}
\hline \multirow[t]{2}{*}{ Need for hospital resources } & No & Yes & OR (univariate) $^{1}$ \\
\hline & $n=1006$ & \multicolumn{2}{|l|}{$n=1689$} \\
\hline \multicolumn{4}{|l|}{ 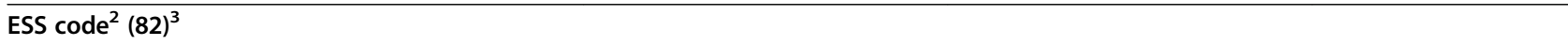 } \\
\hline Abdominal pain & $150(15.3)$ & $178(10.9)$ & $0.68(0.54-0.85, p=0.001)$ \\
\hline Trauma, extremities/thorax ${ }^{4}$ & $59(6.0)$ & $237(14.5)$ & $2.65(1.98-3.59, p<0.001)$ \\
\hline Chest pain & $42(4.3)$ & $214(13.1)$ & $3.36(2.42-4.79, p<0.001)$ \\
\hline Trauma, head & $64(6.5)$ & $178(10.9)$ & $1.75(1.31-2.37, p<0.001)$ \\
\hline Intoxication & $57(5.8)$ & $65(4.0)$ & $0.67(0.47-0.97, p=0.032)$ \\
\hline Dyspnea & $53(5.4)$ & $67(4.1)$ & $0.75(0.52-1.08, p=0.122)$ \\
\hline Non-specific disease & $71(7.3)$ & $57(3.5)$ & $0.46(0.32-0.66, p<0.001)$ \\
\hline Back pain & $75(7.7)$ & $30(1.8)$ & $0.23(0.14-0.34, p<0.001)$ \\
\hline Dizziness & $55(5.6)$ & $42(2.6)$ & $0.44(0.29-0.67, p<0.001)$ \\
\hline Seizures & $19(1.9)$ & $68(4.2)$ & $2.19(1.34-3.77, p=0.003)$ \\
\hline Psychiatric abuse & $47(4.8)$ & $36(2.2)$ & $0.45(0.29-0.69, p<0.001)$ \\
\hline Syncope & $38(3.9)$ & $43(2.6)$ & $0.67(0.43-1.05, p=0.076)$ \\
\hline Trauma, alarm & $8(0.8)$ & $68(4.2)$ & $5.27(2.68-11.94, p<0.001)$ \\
\hline Headache & $33(3.4)$ & $43(2.6)$ & $0.77(0.49-1.24, p=0.278)$ \\
\hline Fever, infection & $24(2.5)$ & $34(2.1)$ & $0.85(0.50-1.45, p=0.534)$ \\
\hline Other $^{5}$ & $185(18.9)$ & $274(16.8)$ & $0.86(0.70-1.06, p=0.167)$ \\
\hline
\end{tabular}

'OR: odds ratio, 95\% confidence interval

${ }^{2}$ The 15 most frequent ESS codes

${ }^{3}$ Number of patients with missing information

${ }^{4}$ Includes trauma to extremity, hip, pelvis and thorax

${ }^{5}$ Includes ESS codes, atrial fibrillation, neurological deficit, pain/swollen extremity, urological problems, allergy

Finally, patients who were given medication by the EMS crew more frequently required hospital resources.

\section{Prehospital assessment according to RETTS among} patients who did and did not require hospital resources (Table 5)

Among patients who did not require hospital resources, abdominal pain, back pain and non-specified sickness were the most common ESS codes in the prehospital assessment. Among patients who required hospital resources, trauma (all subsets added) and chest pain were the most common ESS codes in the prehospital assessment.

\section{Discussion}

The main findings in this study were that, among patients who were brought to hospital by the EMS, 52\% were directly discharged from the ED and, among these patients, a substantial percentage (37\%) did not require hospital resources. Patients who did not require hospital resources were younger than those who did require these resources and they were given a lower priority in the dispatch centre, as well as by the EMS nurse. Among those who did not require hospital resources, the most common cause of contact with the EMS was abdominal pain (15\%).
The most common ESS codes among all the patients who were transported to hospital were abdominal pain, chest pain and dyspnea. However, among these subsets, the majority were admitted to a hospital ward among those with dyspnea and chest pain, whereas, on the other hand, among patients with abdominal pain, the majority were discharged from the ED. In overall terms, patients who were admitted to a hospital ward were 20 years older than those who were discharged from the ED.

Among patients who were admitted to a hospital ward, $56 \%$ were triaged to red or orange (the highest priority), whereas, among patients who were discharged from the ED, $81 \%$ were triaged to green or yellow (the lowest priority). As a result, prehospital triage predicted the subsequent outcome to some extent, particularly among patients who were given a low priority.

In overall terms, $49 \%$ of all the patients who were transported to hospital by the EMS were hospitalised. This finding differs from a US study in which only $20 \%$ of patients with acute symptoms were hospitalised [6]. However, that study used a different triage system.

Previous experience has suggested that $16 \%$ of patients assessed by the EMS are candidates for PC [7]. However, in the present study, $20 \%$ of patients were left at the scene. In addition, 1,006 patients (37\% of those who 


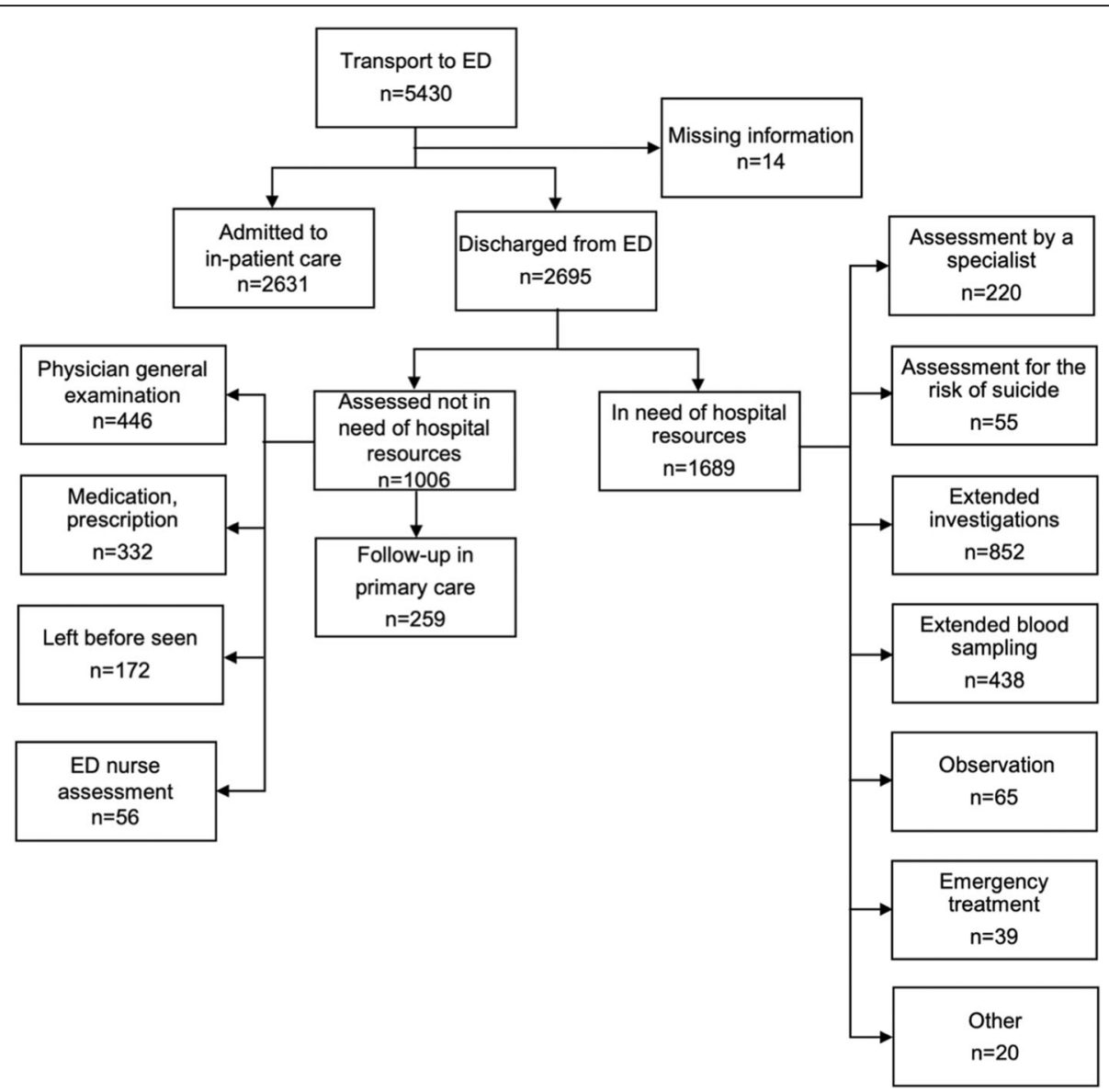

Fig. 1 Distribution of patients assessed and transported to the ED. ED:Emergency department; Extended investigations: computed tomography, ultrasound, lumbar puncture, magnetic resonance imaging, X-ray and scopies; Extended blood sampling: Troponin, d-dimer, NT pro BNP, blood concentrations of drugs; Other: Referral from primary care, in-patient care refusal

were discharged from the ED) were potential candidates for PC. This subset comprised $15 \%$ of all primary missions in the survey $(n=6,712)$. According to the experience acquired from the present study, $20 \%+15 \%=35 \%$ of primary missions in prehospital emergency care are potential candidates for PC. A previous study from Sweden suggested that $85 \%$ of EMS missions did not have a life-threatening or an acute condition [8]. Others have suggested that between $20-40 \%$ of patients admitted to the ED can be handled by PC [9]. In fact, $26 \%$ of the patients in the present study cohort who were discharged from the ED and not assessed as requiring hospital resources were advised to seek a lower level of care.

The majority of patients who were admitted between 08-16 required hospital resources, whereas the opposite was found among patients admitted between 16-22. One of the reasons behind this finding may be that a large number of out-patient clinics close at 16.00. This hypothesis was supported by Fry et al. who reported that many patients explained their admission to the ED by the fact that the out-patient clinic was closed [10].
It is reasonable to assume that a number of patients seek emergency care at the ED due to limited access to PC. This is supported by Tinkler et al., who reported that the median delay to see a doctor in PC was 22 days [11]. It seems as though many patients who visit the ED are not aware of any other alternative [12].

A future alternative introduced in the UK is the "nurse practitioner" (NP) who has an extended education. An NP has increased responsibility as compared with an $\mathrm{RN}$ and is allowed to prescribe medication, among other things [13].

It is possible to discuss whether patients' previous history should be considered in prehospital triage. Previous studies have suggested that comorbidity increases the likelihood that admissions to the ED are the appropriate level of care and that the presence of comorbidity is associated with an increased need for hospital resources $[7,14]$. This was not confirmed in the present study. It is possible to argue that the vast majority of patients in our survey suffered from some previous disease (87\%), which may have created difficulties in addressing this question. 
The three most common causes of contact with the EMS according to RETTS and the ESS code among the patients who were assessed as not requiring hospital resources were abdominal pain, back pain and nonspecific disease. However, on the other hand, many patients were given these ESS codes, admitted to a hospital ward and thus actually required the hospital resources. The EMS nurses in Sweden thus need improved decision-support tools in the prehospital setting to be able to assess patients with these symptoms to the optimal level of care.

\section{Limitation}

The survey was performed in 2016 and several years have passed since then. Some minor changes in the EMS system have taken place. For example, mobile outpatient care teams have been created. However, the routines associated with the prehospital assessment by the EMS nurse have remained the same.

The criteria for using hospital resources can be discussed. In fact, some of the blood samples, such as Troponin, may have already been assessed in PC.

\section{Conclusions}

Among patients who were brought to hospital by the EMS, more than half were directly discharged from the ED. Among these patients, 37\% were assessed as not requiring hospital resources. These patients comprised $15 \%$ of the overall study cohort and may be candidates for primary care.

\section{Abbreviations \\ ECG: Electrocardiogram; ED : Emergency department; EMS : Emergency medical services; ESS: Emergency signs and symptoms; NP: Nurse practitioner; NT-pro BNP: N-terminal pro b-type natriuretic peptide; PC: Primary care; RETTS : Rapid emergency triage and treatment system; RN: Registered nurse; VS: Vital signs; UK: United Kingdom}

\section{Acknowledgements}

The authors wish to acknowledge the Department of Prehospital Emergency Care, Sahlgrenska University Hospital, Gothenburg for support and access to data.

\section{Authors' contributions}

C.M., H.R., F.S., J.H., and C.A. contributed in planning, writing and interpretation of the data. C.M. supervised the statistical analysis and prepared Tables 1, 2, 3, 4 and 5. All authors reviewed the manuscript.

\section{Funding}

The study was supported by the Swedish state under the ALF agreement (ALFGBG-922511). Open Access funding provided by University of Gothenburg.

\section{Availability of data and materials}

Data sets are available from the corresponding author on reasonable request.

\section{Declarations}

\section{Ethics approval and consent to participate}

The Swedish Ethical Review Authority (Gothenburg) approved the study (approval no. 970-15). In this registry study, informed consent was waived.
The requirements of informed consent on scene in this type of study is most often not recommended by the ethical committees in Sweden for the following reasons 1) It is not possible to identify the individual patient since the personal ID number has been coded; 2) Some of the most severe cased could never be contacted in retrospect since they had either died or were in a very poor condition. On top of that logistical reasons and language barriers prevented communication with a number of patients. Thus, the requirement of informed consent would increase the risk of selection bias and thereby impede the reliability of the data. 3) It may be considered unethical to approach the next of kin in such a situation. However, patients who were transported to hospital by the EMS and had expressed their wish for secrecy regarding their personal ID number in case records were excluded from the retrospective data collection in the study. Data have been treated confidentially and were therefore de-identified before analysis. No data have been presented on an individual level. The study is performed in accordance with the relevant guidelines.

\section{Consent for publication}

Not applicable

\section{Competing interests}

The authors declare that they have no competing interests.

\section{Author details}

'Institute of Medicine, Department of Molecular and Clinical Medicine, Sahlgrenska Academy, University of Gothenburg, Gothenburg, Sweden. ${ }^{2}$ Department of Prehospital Emergency Care, Sahlgrenska University Hospital, Gothenburg, Sweden. ${ }^{3}$ Centre for Prehospital Research, Faculty of Caring Science, Work Life and Social Welfare, University of Borås, Borås, Sweden.

Received: 4 April 2021 Accepted: 20 July 2021

Published online: 15 December 2021

\section{References}

1. Tygesen GB, Håkonsen SJ, Uhrenfeldt L. Effectiveness of decision tools used to identify adult patients suitable for early discharge from emergency departments: a systematic review protocol. JBI Database of Systematic Rev Implementation Rep. 2016;14(1):67-76. https://doi.org/10.11124/jbisrir-201 6-1801.

2. Berg LM, Ehrenberg A, Florin J, Östergren J, Göransson KE. Significant changes in emergency department length of stay and case mix over eight years at a large Swedish University Hospital. Int Emerg Nurs. 2019;43:50-5. https://doi.org/10.1016/j.ienj.2018.08.001.

3. Berg LM, Ehrenberg A, Florin J, Östergren J, Discacciati A, Göransson KE. Associations Between Crowding and Ten-Day Mortality Among Patients Allocated Lower Triage Acuity Levels Without Need of Acute Hospital Care on Departure From the Emergency Department. Ann Emerg Med. 2019b; 74(3):345-56. https://doi.org/10.1016/j.annemergmed.2019.04.012.

4. Magnusson C, Herlitz J, Axelsson C. Patient characteristics, triage utilisation, level of care, and outcomes in an unselected adult patient population seen by the emergency medical services: a prospective observational study. BMC Emerg Med. 2020;20(1):1-19. https://doi.org/10.1186/s12873-020-0302-x.

5. Weinick RM, Burns RM, Mehrotra A. Many emergency department visits could be managed at urgent care centers and retail clinics. Health Aff. 2010; 29(9):1630-6. https://doi.org/10.1377/hlthaff.2009.0748.

6. Honigman LS, Wiler JL, Rooks S, Ginde AA. National Study of Non-urgent Emergency Department Visits and Associated Resource Utilization. West J Emerg Med. 2013;14(6):609-16. https://doi.org/10.5811/westjem.2013.5.1 6112.

7. Norberg G, Wireklint Sundström B, Christensson L, Nyström M, Herlitz J. Swedish emergency medical services' identification of potential candidates for primary healthcare: Retrospective patient record study. Scand J Prim Health Care. 2015;33(4):311-7. https://doi.org/10.3109/02 813432.2015.1114347.

8. Hjälte L, Suserud BO, Herlitz J, Karlberg I. Why are people without medical needs transported by ambulance? A study of indications for pre-hospital care. Eur J Emerg Med. 2007;14(3):151-6. https://doi.org/10.1097/MEJ.0b013 e3280146508.

9. Whyatt D, Tuson M, Haynes E, Mountain D, Nagree Y, Vickery AW. Burden of primary care-type emergency department presentations using clinical 
assessment by general practitioners: A cross-sectional study. Emerg Med Australas. 2019;31(5):780-6. https://doi.org/10.1111/1742-6723.13255.

10. Fry MM. A systematic review of the impact of afterhours care models on emergency departments, ambulance and general practice services. Australas Emerg Nurs J. 2011;14(4):217-25. https://doi.org/10.1016/j.aenj.2011.09.001.

11. Tinkler S, Sharma R, Pal S, Susu MR, Stano M. Offers of appointments with nurse practitioners if a requested physician is unavailable. J Am Assoc Nurs Pract. 2017;29(4):209-15. https://doi.org/10.1002/2327-6924.12404.

12. Northington W, Brice J, Bin Z. Use of an emergency department by nonurgent patients. Am J Emerg Med. 2005;23(2):131-7. https://doi.org/10.1 016/j.ajem.2004.05.006

13. NHS (2015). Do I need to see the doctor or the nurse practitioner? Collected from https://www.saltscarsurgery.nhs.uk/website/A81054/files/ Nurse\%20Practnr\%20lftt\%20-\%202015\%20Nov.pdf [2021-04-04]

14. Carret MLV, Fassa ACG, Domingues MR. Inappropriate use of emergency services: a systematic review of prevalence and associated factors. Cad Saúde Pública. 2009;25(1):7-28. https://doi.org/10.1590/S0102-311X20090001 00002.

\section{Publisher's Note}

Springer Nature remains neutral with regard to jurisdictional claims in published maps and institutional affiliations.

Ready to submit your research? Choose BMC and benefit from:

- fast, convenient online submission

- thorough peer review by experienced researchers in your field

- rapid publication on acceptance

- support for research data, including large and complex data types

- gold Open Access which fosters wider collaboration and increased citations

- maximum visibility for your research: over $100 \mathrm{M}$ website views per year

At BMC, research is always in progress.

Learn more biomedcentral.com/submissions 